\title{
El pensamiento político de Josep Torras i Bages
}

The political thought of Josep Torras i Bages

\author{
Miquel Bordas Prószynski ${ }^{1}$ \\ Universidad Complutense de Madrid
}

Recibido: 15.12.2020

Aceptado: 29.12.2020

\section{Resumen}

Exposición correspondiente al acto de defensa ${ }^{2}$ de la Tesis Doctoral del Dr. Bordas Prószynski, intitulada El pensamiento político de Josep Torras i Bages, en la que se recorre el marco histórico-cultural de la Cataluña de finales del siglo XIX y de comienzos del XX, para apreciar la aportación de la persona y de la obra de Josep Torras i Bages, obispo de Vic durante los años 1899 a 1916. El resultado de la investigación ofrece una síntesis de su pensamiento político, especialmente por lo que se refiere a su doctrina regionalista vindicando la tradición cristiana de Cataluña.

\footnotetext{
1 mibordas@ucm.es https://orcid.org/0000-0001-8518-4379

https://scholar.google.es/citations?hl=es\&user=uZsYedsAAAAJ

${ }^{2}$ Se reproduce el texto, con ligeras adaptaciones para las necesidades de la presente publicación, de la exposición leída el 22 de enero de 2016, de defensa de la tesis doctoral realizada bajo la dirección del Prof. Dr. D. Evaristo Palomar Maldonado. El acto público de defensa en la Facultad de Derecho de la Universidad Complutense tuvo lugar ante el tribunal formado por: el Prof. Dr. José Iturmendi Morales (presidente), el Prof. Dr. D. Emilio Suñé Llinás (secretario), el Prof. Dr. D. Francisco J. Paredes Alonso, el Prof. Dr. D. José Ma Alsina Roca y la Prof. Dra. Da. María Lacalle Noriega; recibiendo la investigación doctoral la calificación de sobresaliente cum laude por unanimidad. Se ha enriquecido dicho texto con alguna nota ilustrativa o explicativa al pié de página y se ha incluido una bibliografía mínima de referencia, con posiciones bibliográficas aparecidas con posterioridad al depósito de mi memoria para doctorado y al acto de defensa del mismo.
} 
Palabras clave: Torras i Bages, Tradición, Comunidad política cristiana, Liberalismo, Regionalismo catalán.

\begin{abstract}
Text corresponding to the public $\mathrm{PhD}$ dissertation entitled The political thought of Josep Torras i Bages by Dr Bordas Prószynski, which investigates the historical and cultural background in Catalonia between the end of the nineteenth century and the beginning of the twentieth century, in order to assess the relevance of the figure and works of Josep Torras i Bages, who was bishop in the Catalan city of Vic from 1899 till 1916. The research provides a synthesis of the political thought of the author, especially with regard to his regionalist doctrine vindicating the Christian tradition of Catalonia.
\end{abstract}

Keywords: Torras i Bages, Tradition, Christian political community, Liberalism, Catalan regionalism.

\title{
Motivación
}

Iniciado en la Filosofía del Derecho por parte del Prof. Dr. Evaristo Palomar Maldonado, de quien aprendí, entre otras cosas, que el Derecho no es desde luego meramente un conjunto de normas, ni la mera voluntad normativa dotada de coactividad institucionalizada ${ }^{3}$, ni la expresión de un acto de soberanía, ni tantas cosas que se dicen y han sido repetidas, al superar los estudios de licenciatura en Derecho, decidí proseguir los estudios, inscribiéndome en los correspondientes cursos de doctorado del Departamento de Filosofía del Derecho, Moral y Política I de la Facultad de Derecho de la Universidad Complutense. Pronto descarté un tema más genérico de investigación como era el de las relaciones entre la justicia y la caridad, centrando mi atención sobre la persona y obras del obispo de Vic, Josep [José] Torras, del cual desconocía casi todo, salvo su relevancia en el panorama del catalanismo y en el pensamiento tradicional catalán por ser el autor de una obra capital, La tradició catalana. Tras

\footnotetext{
${ }^{3}$ Cf. Díaz, E., Sociología y Filosofía del Derecho, Ed. Taurus, Madrid 1980, p. 50.
} 
obtener el Diploma de Estudios Avanzados, procedí con el periodo de investigación, antes de abordar la última etapa de elaboración del trabajo doctoral.

\section{Labor realizada y metodología}

A la hora de profundizar en el objeto de estudio resultaba, en todo caso, indispensable aproximarme a la biografía del autor estudiado, así como a su obra escrita, incluyendo su extenso epistolario. Paralelamente, se hacía evidente la necesidad de situar al personaje en las coordenadas de su tiempo y espacio, ya sea desde el punto de vista histórico, político, jurídico o cultural e intelectual. A tal fin, dediqué un largo tiempo a la localización, selección, consulta y compilación ordenada de un ingente material bibliográfico, que siempre parecía insuficiente y que con frecuencia parecía imposible de delimitar. Y es que, para entender nuestros lodos contemporáneos, los polvos del siglo XIX español han sido y serán objeto de apasionados e incesantes análisis y valoraciones. La «cuestión catalana» y el «procés» independentista auspiciado por las autoridades locales de Cataluña, recibiendo el apoyo creciente de una parte importante de la sociedad catalana actual ${ }^{4}$ no se entenderían, por ejemplo, sin profundizar en

\footnotetext{
${ }^{4}$ Movimientos que, tras la defensa de la presente investigación doctoral, tuvieron su momento álgido con la convocatoria, con arreglo a la Ley del Parlamento de Cataluña 19/2017, de 6 de septiembre, del referéndum de autodeterminación (y normativa complementaria, incluyendo el Decreto de la Generalitat de Cataluña, de la misma fecha, de convocatoria del Referéndum de Autodeterminación de Cataluña), cuya disposición legal autonómica fue declarada inconstitucional y nula por el Tribunal Constitucional español el 16 de octubre de 2017, mediante su sentencia $n^{\circ} 114 / 2017$, dictada en el recurso de inconstitucionalidad 4334/2017, interpuesto por el Presidente del Gobierno español; y la posterior celebración fáctica del citado referéndum el 1 de octubre de 2017, que no pudo ser evitada por las fuerzas de seguridad del Estado español. Las Resoluciones del Pleno del Parlamento de Cataluña de 27 de octubre de 2017, denominadas "Declaración de los representantes de Cataluña" y "Proceso constituyente", fueron anuladas mediante auto del Tribunal Constitucional, de 8 de noviembre de 2017. En relación con la declaración del Presidente de la Generalitat el 10 de octubre de 2017, en su comparecencia ante el Parlamento de Cataluña, en la que asumía «el mandato de que Cataluña se convierta en un Estado independiente en forma de república», para segundos después, sin embargo, proponer que «el Parlamento suspenda los efectos de la declaración de independencia», y su desatención al requerimiento previo del Consejo de Ministros, de 11 de octubre de 2017, provocó la aplicación del artículo 155 de la Constitución española, autorizada por el Senado español, que aprobó las medidas requeridas por el Gobierno español, incluyendo el cese del Presidente de la Generalitat de Cataluña, del Vicepresidente y de los Consejeros que integran el Consejo de Gobierno de la Generalitat de Cataluña, así como la convocatoria de elecciones al Parlamento autonómico de Cataluña para el día 21 de diciembre de 2017. Paralelamente, mediante sentencia 124/2017, de 8 de noviembre de 2017, dictada en el recurso de inconstitucionalidad 4386/2017, interpuesto por el Presidente del Gobierno, el Tribunal Constitucional declaró la inconstitucionalidad y la nulidad de la Ley del Parlamento de Cataluña 20/2017, de 8 de septiembre, denominada «de transitoriedad jurídica y fundacional de la República». Finalmente, el 14 de octubre de 2019, mediante sentencia 459/2019, el Tribunal Supremo español condenó por la organización del citado referéndum de independencia a determinados consejeros del Gobierno
}

Volumen 1. Número 1. Enero - Junio 2021 ISSN: 2745-0333 (En línea) 
las raíces más remotas del catalanismo y, más en general, en el XIX español. Ello, sin perder de vista la amplia bibliografía torrasiana, específica e incidental, a veces laudatoria y otras muchas críticas. Por consiguiente, habida cuenta que la presente es una investigación que versa más bien sobre las ideas que sobre los hechos, aunque necesariamente tenga que presuponer tales hechos, mi esfuerzo se dirigió principalmente al análisis de los datos arrojados por la bibliografía disponible. La interpretación de sus resultados me permitió culminar la última fase de ese trabajo, acaso la más dura pero también la más gratificante: la progresiva redacción de la tesis y la formulación de las conclusiones.

Aunque Josep Torras i Bages es un eclesiástico y pensador conocido en determinados ámbitos, conviene referir brevísimamente los hitos más relevantes de su vida y de su obra. Nacido en 1846 en Les Cabanyes, cerca de Vilafranca del Penedés, provincia de Barcelona (España), estudió en el Instituto y en la Universidad de Barcelona, donde se graduó en Filosofía y Letras, así como en Derecho en 1869, siendo testigo muy próximo del movimiento cultural de la «Renaixença» catalana. Tras doctorarse con una tesis sobre el matrimonio cristiano, descartó la toga y eligió el traje talar, siguiendo la llamada de la vocación sacerdotal. Se dirigió en un primer momento al Seminario de Vic, localidad situada en el hinterland catalán, atraído por el tomismo, que constituía -sin que se hubiese promulgado la Aeterni Patris de León XIII- la médula de la formación impartida en dicho centro. Fidelidad a Santo Tomás que Torras i Bages profesará toda su vida. Tras las inquietudes vividas durante la I República española y la III Guerra carlista, su vida adulta se desplegaría en el periodo de la Restauración liberal española. Una vez ordenado presbítero, no asumió cargos eclesiásticos, dedicándose a la asistencia espiritual en Barcelona de diversas congregaciones religiosas femeninas, así como de seglares y seminaristas. Su carácter retraído fructificó en la publicación de varios escritos y artículos apologéticos de temática religiosa y social. Siguen gozando de especial popularidad en la devoción del pueblo cristiano su Mes del Sagrat Cor (1879), así como su Mes en honor del Patriarca Sant Josep (1894). En cambio, no se involucró directamente en las agrias

de la Generalitat de Cataluña, incluyendo a su Vicepresidente, por sendos delitos de sedición y de malversación de fondos, así como a algunos consejeros por el delito de desobediencia. Otros consejeros, incluyendo el Presidente de la Generalitat de Cataluña, no han podido ser juzgados todavía por no haber sido hallados en España. 
polémicas entre mestizos e integristas, que el mismo León XIII había intentado atajar sin éxito con la encíclica dirigida a los católicos españoles Cum multa (1882), si bien Torras i Bages manifestó su postura, alejada del integrismo, en el opúsculo El clero en la vida social moderna (1888). De sus aportaciones, la más reconocida indudablemente es el libro La tradició catalana, editado en 1892 (siendo la primera parte del mismo una recopilación de artículos aparecidos anteriormente en el semanario La Veu del Montserrat dirigido por su amigo, el canónigo Jaime Collell). Se trata de una meditación sobre la naturaleza o alma, esto es, la identidad de Cataluña, que se analiza en la segunda parte de esta obra representada en una selección de las figuras más señeras de la historia intelectual del Principado (que él extiende a los Reinos de Mallorca y Valencia, integrados históricamente en la Corona de Aragón y que comparten la misma lengua de origen). Al mismo tiempo, esta obra constituye un alegato contra la influencia del cesarismo, primero, y el liberalismo revolucionario después, por ser antitéticos al modelo de sociedad cristiana del regionalismo tradicional que él propugnaba para Cataluña. Paulatinamente, su relevancia intelectual le convertiría en una autoridad, tanto en el catalanismo, como en el pensamiento tradicional catalán. El Dr. Torras participó como consiliario de ciertas asociaciones, como es Círculo Artístico de San Lucas, formando asimismo parte de distintas instituciones culturales barcelonesas, llegando a presidir los Juegos Florales de Barcelona de 1899. En dicho año fue nombrado obispo de la diócesis de Vic, sucediendo en el cargo a Mons. José Morgades (1826-1901), que había sido trasladado a la sede de Barcelona. Permanecería en dicha diócesis vicense hasta su muerte, acaecida el 7 de febrero de 1916. De su episcopado son especialmente reseñables sus firmes intervenciones públicas en defensa de los derechos de la Iglesia ante las tentativas laicistas de los gobiernos españoles de turno, así como, en general, su cuerpo magisterial formado por más de 50 pastorales que trascendieron los límites de su obispado e incluso merecieron las alabanzas de 
los pontífices San Pío $\mathrm{X}^{5}$ y Benedicto $\mathrm{XV}^{6}$. En todos estos años, como revela su epistolario, Torras i Bages acompañó espiritualmente a diversos personajes que conformaron la vida cultural y política catalana de su tiempo. A todo ello hay que añadir el reconocimiento de una santidad de vida del obispo Torras que justificaría la apertura de su proceso de beatificación y que a estas fechas no ha concluido ${ }^{7}$. El interés en la figura del autor estudiado se acrecienta cuando comprobamos que en la literatura científica de referencia se le ha descrito, entre otras calificaciones, como el desactivador efectivo del integrismo en Cataluña, el teorizador

${ }^{5}$ El Papa Sarto le envió una carta de reconocimiento al Obispo de Vic por su pastoral Dios y el César, fechada en la fiesta del Patriarca San José, 19 de marzo de 1911, que es uno de los textos universalmente más conocidos del Prelado catalán y en el que este salía al paso de la «Ley del Candado» de José Canalejas, que pretendía restringir la libertad de las congregaciones religiosas en España y ahondar en la separación del Estado y de la Iglesia. Expresaba San Pío en su carta laudatoria, de 1 de mayo de 1911, dirigida al Obispo catalán: «realmente en ella te muestras obispo, tal como lo describe el Apóstol, "guardador de las verdades de la fe según le han sido enseñadas, a fin de ser capaz de instruir en la sana doctrina y argüir a quienes la contradigan". Y, en verdad, que con sana doctrina y perfectamente acomodada a las circunstancias de la sociedad has instruido al pueblo que te fue confiado, exponiendo e ilustrando magníficamente los principios, conforme a los que deben componer sus mutuas relaciones ambas potestades, eclesial y civil». La versión completa del texto original en latín de la misiva de San Pío X figura transcrita, junto con su traducción al catalán por parte de Fortián Solà, recogida de su biografía torrasiana, en el v. IV del Epistolari, Publicacions de l'Abadia de Montserrat, Barcelona 1997, pp. 218 219 , nota 1.

${ }^{6}$ El Papa Della Chiesa, a su vez, felicitó a Mons. Torras i Bages por su pastoral El internacionalismo papal (1915), que glosaba las exhortaciones pontificias encaminadas a la reconciliación de una Europa que se desangraba en medio de la Primera Guerra Mundial. El obispo de Vic remitía el 18 de diciembre de 1915 -a menos de dos meses de su muerte - al Cabildo de la Catedral de Vic la transcripción de la copia de la carta de Benedicto XV, que le había enviado el Nuncio el 15 de diciembre 1915. El texto original y la traducción de Fortián Solà se puede consultar en el v. IV del Epistolari, op. cit., pp. 255-256: «Tu amor y servicio a la Sede Apostólica, bien conocidos de Nos ya de ha mucho tiempo, los hemos visto confirmados con nuevos y brillantes documentos, al ser elevados por la misericordia divina a esta plenitud de poder. Ahora aumenta maravillosamente en Nos el concepto de tu virtud la pastoral recientemente publicada con el título: EL INTERNACIONALISMO PAPAL, la cual nos ofrece al mismo tiempo la ocasión más oportuna para expresar, como queríamos y deseábamos vivamente, Nuestra voluntad hacia ti. A penas hemos leído otra cosa con mayor satisfacción; todo lo que nos proponíamos al escribir nuestra EXHORTACIÓN a los pueblos beligerantes y a sus directores, lo has comprendido con penetrante juicio, llegando al fondo de Nuestro pensamiento y reproduciéndolo tan bien, que quien leerá tu escrito verá las razones inspiradoras de Nuestros actos en todo aquel asunto de la guerra, y la finalidad de Nuestras exhortaciones a la paz. Hay, por consiguiente, motivo para felicitarte por el fruto abundante de tu ingenio y estudio, y para manifestarte, además, el deseo que las enseñanzas dirigidas a la instrucción de los diocesanos, sean largamente difundidas, para que a todos pueda alcanzar la fuerza de Nuestros pensamientos e intenciones, y estimar su utilidad como corresponde.».

${ }^{7}$ La apertura del proceso de beatificación tuvo lugar en 1931, concluyéndose a nivel diocesano. El proceso siguió su cauce superando las diferentes fases. En 1963 fue promulgado el decreto sobre los escritos del siervo de Dios. En 1966 y 1982 el episcopado español, así como los obispos de la provincia tarraconense, remitieron sendas peticiones a Roma solicitando la beatificación del Dr. Torras. En 1987 la Sagrada Congregación para las Causas de los Santos promulgó el decreto sobre la autoridad y fuerza de los procesos informativos de Vic y de Barcelona. Los padres cardenales y los obispos, en la sesión ordinaria del día 7 de abril de 1992, reconocieron la heroicidad de las virtudes practicadas por el obispo Josep Torras i Bages. El Decreto, de 13 de junio de 1992, aprobado por Juan Pablo II, resalta que Torras i Bages fue un «pastor insigne» y ejerció loablemente su sacerdocio. 
ultramontano y el vindicador de la tradición catalana, un represor de las ansias modernizantes y nacionalistas o incluso el inquisidor nacional ${ }^{8}$.

Por tanto, el estudio acometido de la biografía y la obra de Mons. Torras i Bages requería situarle en su contexto, a la vista de los grandes movimientos sociales, culturales y políticos de su tiempo. Asimismo, esto me obligaba a confrontarle con las corrientes ideológicas más importantes que confluyeron a lo largo del siglo XIX y principios del XX en España y, especialmente, en Cataluña. A medida que se entraba en la materia, se fueron suscitando nuevos retos y preguntas de investigación, inicialmente no contempladas, pero que no quise rehuir. Así, debía trazarse inicialmente el marco genérico de crisis de la Hispanidad o de la Cristiandad en España, que, mediando el despotismo ilustrado, precedió a la aparición del liberalismo revolucionario en dicho país. En especial, para Cataluña este momento de decadencia histórica quedaría simbolizado tópicamente por el Decreto de Nueva Planta de Cataluña, de Felipe V (1716), por el que se derogaban las leyes e instituciones públicas propias que regían en el Principado de Cataluña, tras la Guerra de Sucesión española. En suma, debía rastrear las raíces del liberalismo en una Cataluña anclada secularmente en su modo de vida tradicional, así como su relación más o menos remota con la «Renaixença» decimonónica. En este sentido, convenía analizar la influencia que habría ejercido el romanticismo ambiental en la conformación de las sensibilidades, ideologías y actitudes en los distintos campos de la vida del siglo xix. Ello me permitiría valorar las reacciones instintivas de las élites barcelonesas frente a las radicales transformaciones sociales e inquietudes que experimentara en aquel tiempo aquella Cataluña tan convulsa y que estas mismas élites también habían desencadenado. Al mismo tiempo, no me dejaba de sorprender el vigor de otra Cataluña, la Cataluña interior, indómita y acaso menos sofisticada, empeñada en resistirse a los aires más liberales procedentes de la marina. Consiguientemente, ocurría atender a los resortes religiosos e intelectuales que sostenían aquellos ambientes realistas y carlistas catalanes a lo largo del siglo XIX en su macabaica lucha por la Tradición y contra la Revolución. La tarea se complicaba por tratarse de un pensamiento tradicional del que carecemos todavía de un

\footnotetext{
${ }^{8}$ Desde una perspectiva más hagiográfica, por su parte, se le ha calificado como Obispo por antonomasia, Obispo de Cataluña, Obispo de santa memoria, Padre y Patriarca espiritual de Cataluña o Santo Padre de los tiempos modernos.
} 
estudio completo y definitivo. Asimismo, era necesario considerar las circunstancias que pudieron contribuir a la desarticulación de estas corrientes tradicionales tan viscerales y que aglutinaba el carlismo catalán. La interpretación de las claves históricas no podía perder de vista el posicionamiento de los pastores locales de la Iglesia frente a la pretensión de construir el Estado liberal, siquiera en su vertiente moderada, sobre unas bases antitéticas a los principios del modelo de la sociedad política cristiana. Teniendo en cuenta la «provincialización» del Principado de Cataluña, acaecida en el siglo XVIII, resultaba imprescindible estudiar los desarrollos de conciencia de los pensadores catalanes entorno al llamado «encaje» de Cataluña en España a la largo de la centuria diecinueve, o lo que se ha llamado el lenguaje del doble patriotismo y del que Prat de la Riba tanto abominaba. Singularmente, se trataba de explicar cómo se había llegado a la reformulación abiertamente nacionalista, defendida por unos jóvenes intelectuales como el que acabo de citar, muchos de ellos discípulos del mismo Torras i Bages, los cuales liderarían la política catalana de principios del siglo XX en clave catalanista.

Estas son sólo algunas de las cuestiones a las que procuré dar repuesta en mi trabajo para contextualizar una figura tan rica de matices como es la del obispo Torras, tan hijo de su tiempo. En todo caso, en esa tarea de contextualización y, por tanto, de interpretación histórica, traté de evitar simplificaciones hermenéuticas materialistas como las que propugna el omnipresente marxismo, lectura materialista que, dicho sea de paso, parece perpetuarse en la historiografía española de referencia. Otro obstáculo en dicha contextualización fueron precisamente ciertas relecturas de nuestro pasado empeñadas en hacernos creer que la Historia la mueven dinamismos inmanentes e inevitables de autodeterminación o liberación progresiva de diverso signo, orientados todos ellos hacia la reconstrucción de un estado natural de libertad indeterminada de la Humanidad consciente.

En definitiva, me hago cargo de que, en una primera impresión, podría parecer que el ámbito de esta indagación preliminar y previa al estudio de la teoría política del Dr. Torras -es decir, el grueso de la primera y segunda parte de la tesis- resultaba desmesurado. Pero entiendo que era un esfuerzo imprescindible, para viajar en el tiempo al mismo escenario que vio nacer, 
crecer y morir al obispo de Vic. Es decir, tenía que contrastar y abordar las mismas cuestiones que suscitaron o inspiraron la pluma enérgica de Mons. Torras i Bages.

\section{Contenido}

Hecha esta introducción, quiero destacar ahora las principales líneas que configuran la estructura de la investigación. En la primera parte planteo la situación de transición histórica, referida específicamente al ámbito español y catalán, desde lo que convencionalmente se conoce como Antiguo Régimen (aunque yo prefiero denominar como Cristiandad), hasta el actual Estado social y democrático de Derecho. Donde se invirtió la primacía de lo espiritual sobre lo temporal. Obviamente, no fue un proceso pacífico y suscitó reacciones de distinto tipo. De ahí la importancia que el liberalismo español otorgó a las desamortizaciones eclesiásticas y civiles para erradicar así la sociedad estamental y conseguir consolidar la revolución entre las oligarquías españolas. Así, las élites aristocráticas y burguesas, ante las nuevas convulsiones sociales y obreristas, procuraron gobernar conservando un nuevo orden, que preservara en todo caso los nuevos principios liberales. Ante la pretensión emancipadora de articular una política sin Cristo, la Iglesia no desatendió el combate espiritual por las almas y por las sociedades, de ahí el magnífico magisterio pontificio del Beato Pío IX, León XIII y San Pío X. Ello sin perjuicio de los regímenes concordatarios, como el de 1851 con el Reino de España, que la Santa Sede tuvo a bien celebrar transaccionalmente con los gobiernos de hecho.

Por otra parte, para lo que nos aquí nos ocupa, el centralismo liberal, heredado del despotismo ilustrado, deshacía necesariamente la cohesión histórica de los reinos españoles. La variedad de los modos de ser históricos y regionales de las Españas debía ser sacrificada al ideal administrativo de una Nación uniformada, moderna y liberal, a imagen de la vecina Francia. Ciertamente, las reacciones y repliegues periféricos no se hicieron esperar, estimuladas por el ambiente romántico e historicista, que a la sazón también inspiraba el constitucionalismo español. Es en aquella época que, por esta causa, se generaron los resentimientos que, exasperados y socializados hasta niveles insospechados, presiden la vida colectiva de 
numerosas comunidades históricas en España. Ello explicaría las corrientes que desembocaron en la «Renaixença» catalana y el movimiento catalanista. Sin embargo, a lo largo de esta síntesis, no he querido perder de vista que en aquella Cataluña se mantuvo viva la llama de una sociedad arraigada en su lealtad a Dios y al Rey legítimo, así como a lo que quedaba de sus constituciones y costumbres. No conviene caer en simplificaciones y escindir esa Cataluña interior o montañesa de la «otra» Cataluña, la fabril y liberal, puesto que ambas, a la par que se combatían, estaban interrelacionadas y se alimentaban mutuamente. Todo ello en un marco de elevado crecimiento demográfico y también económico a la largo de todo el siglo XIX. Por otra parte, hasta su clausura, este reducto tradicional mantenía sus expresiones intelectuales y literarias, gestadas en los numerosos conventos y en la propia Universidad de Cervera en sus postrimerías. Academia joh paradoja! que había sido creación del Solón de Cataluña, el denostado Felipe V, y feudo del eclecticismo jesuítico.

A este respecto, quise reflejar especialmente los juicios históricos y políticos de Torras i Bages sobre dicha transición. A lo largo de esta parte de mi investigación, podemos tomar nota, por ejemplo, de algunas de sus valoraciones severas sobre el siglo XIX, que describe como un heredero dilapidador de esta tradición que él defiende. Pero sobretodo contemplamos su apología del régimen de la Cristiandad y del Papado, las críticas al cesarismo y al concepto de patria liberal española, las condenas al socialismo y la defensa de un romanticismo literario, por su intento de restauración del pasado. Ello, como a Balmes, le sitúa a Torras i Bages en una posición intermedia, entre el pensamiento tradicional y el de la escuela apologética catalana, que tan finamente estudió José María Alsina Roca en El tradicionalismo filosófico en España. Su génesis en la generación romántica catalana. Se explica así la línea que adoptaría la corriente del vigatanismo liderado por Torras i Bages y Collell, marcando distancias con el integrismo y el mesticismo, pero que suponía un particular ralliement catalán. A la larga, la vía catalanista católica, como estudió el Prof. Cacho Viu, se presentaría ya declaradamente nacionalista como la única opción legítima para los católicos catalanes, miembros de una verdadera Iglesia catalana que profesaba un catolicismo «abierto» y dialogante, opuesto a la caverna castellana, en lo que Cardó llamaba «la buena tradición». Estaríamos ante una generación que se decía discípula del Dr. Torras, identificada con los 
planteamientos de ordenación o nacionalización de Cataluña por parte del Noucentisme, esto es, la acción cultural e institucional del catalanismo político durante el primer tercio del siglo XX, especialmente mediante el instrumento de la Mancomunidad, en la aspiración de construir un «cuerpo de Estado» autónomo para Cataluña.

Tras acotar este marco histórico en la primera parte, en la segunda parte de la investigación, consideré las principales corrientes ideológicas presentes en la Cataluña decimonónica y que acompañaban o justificaban, las más de las veces mezcladas entre ellas, las distintas posiciones políticas. Con la particularidad de que, a principios del siglo XX, un sacerdote catalán, Salvador Bové, ya hablaba de la existencia de una «filosofía nacional catalana», en un sentido parecido al de Eugenio d'Ors. Es decir, una filosofía que se distinguía principalmente porque se expresaba en idioma catalán. Ciertamente, para formular el principio de nacionalidades, el nacionalismo catalán haría suyas las aportaciones espiritualistas de la escuela histórica, así como las elucubraciones racionalistas krausistas sobre la nacionalidad orgánica. A su vez, a pesar de que el campo filosófico de la Iglesia también se vio inundado por todo tipo de tendencias ajenas a su propia tradición, destaca la pervivencia del tomismo en la enseñanza eclesiástica. De modo que la publicación de la Aeterni Patris no supuso en algunos ámbitos, como el Seminario de Vic, donde acudió Torras i Bages a estudiar un par de cursos tras licenciarse en Derecho por la Universidad de Barcelona, una restauración de la escolástica en Cataluña, toda vez que no se había llegado a producir una verdadera ruptura con la «rancia» escolástica. Precisamente, nuestro autor, que se había iniciado en la Filosofía bajo el maestrazgo de Llorens i Barba, quien pretendía fundir la escuela del sentido común con la escocesa, descartaría ese psicologismo semicartesiano, apostando decididamente por la Summa de Santo Tomás, desde una orientación eminentemente práctica (centrando su interés más inmediato en la filosofía moral).

Así las cosas, en esta segunda parte quise rescatar también los juicios del Dr. Torras relativos a las corrientes filosóficas que convivían en la Cataluña finisecular. Así, nuestro eclesiástico pondera el tomismo básicamente como el sistema genuino de pensamiento de Cataluña, habiendo sido los frailes predicadores los encargados de la alta enseñanza en esa tierra. Para 
él, en efecto, únicamente la filosofía escolástica lograba sintetizar lo concreto y lo ideal. Al mismo tiempo, Torras i Bages criticaba las otras ideologías circunstantes. Recriminaba al tradicionalismo filosófico que prescindiera del hombre, esto es, de la razón individual, abocándonos al fideísmo. Al cartesianismo le echaba en cara su escepticismo, cuya duda universal imposibilitaba cualquier ideal o fin. Respecto al idealismo alemán, en cambio, llegaba a calificar como ciencia del mal a la filosofía de la autodeterminación de Kant y criticaba el supuesto hegelianismo de Almirall, por propugnar un Estado absorbente y totalitario. Finalmente, del positivismo, cuya metodología no despreciaba, reprochaba su base naturalista o materialista, cerrada a cualquier trascendencia.

Dos apartados complementan esta segunda parte de mi investigación. El primero de ellos está dedicado específicamente a la línea de pensamiento tradicional catalán de la primera mitad del siglo XIX, a la que se ya realizaron ciertas alusiones en la primera parte. Constato al respecto que no disponemos todavía de un estudio de conjunto de los autores que componen esta corriente, algunos, como Vicente Pou y Magín Ferrer, titulares de una obra prolífica y solvente. Pero, en todo caso, este capítulo me sirvió para delimitar los principios sobre los que se construía el orden intelectual de la tradición española y catalana, opuesto tajantemente a las novedades extranjerizantes. Para abreviar, podemos sintetizar dicha tradición política con el trilema de Dios, Patria y Rey, o el binomio: Religión y Monarquía. Asimismo, pude evaluar hasta qué punto el pensamiento de Torras i Bages se mantiene fiel y compatible con los planteamientos tradicionales y dónde se produce una evolución divergente. En el último capítulo de esta segunda parte, se incide en la reflexión de una serie de intelectuales catalanes de todo el siglo XIX acerca del papel que debe desempeñar Cataluña en el conjunto de España. Así, en un devenir cronológico, podemos seguir la «cuestión catalana» a través de perspectivas provincialistas, federalistas, particularistas, regionalistas o ya, llegando a Prat de la Riba, netamente nacionalistas. Salvo en esta última posición, se comprueba en general la conciencia hispánica y la participación de aquellos catalanes en la construcción de España como nación liberal, insistiendo al mismo tiempo en los rasgos distintivos de su identidad regional. Ello me permitió también calibrar las aportaciones o las deudas ideológicas del regionalismo del propio Torras i Bages respecto del entorno intelectual y político catalán del momento. 
En este punto, estábamos ya en disposición de asomarnos al contenido de la filosofía política de Josep Torras i Bages y que es objeto de la tercera y última parte de la investigación. En primer lugar, conviene mencionar algunas claves de su pensamiento sobre la cosa pública. Llama la atención, ante todo, su visión providencialista de la realidad social y política en lo que sería una adaptación de la teología de la historia que desarrolló el jesuita francés Enrique Ramière y sobre cuyo pensamiento versó el propio trabajo de doctorado del director de mi tesis, el Prof. Dr. D. Evaristo Palomar ${ }^{9}$. Como ley general, sienta el Dr. Torras que Dios, en su amor, gobierna a los hombres y que, imperfectamente, los hombres pueden conocer sus designios. Ello explica la predestinación social de los pueblos, sujetos a la ley divina, pero garantizados en su espontaneidad y modo de ser peculiar. Providencia que actúa, sin embargo, ordinariamente a través de las causas segundas. Así, este gobierno divino redunda en un cristianismo social, inspirado por la caridad y caracterizado por el genuino progreso. En cambio, el laicismo moderno se distingue precisamente por haber querido echar a Dios de la sociedad, suplantándolo por el Estado moderno, la Anti-Iglesia, gobernada por el egoísmo, la concupiscencia y la soberbia.

Otro presupuesto fundamental del pensamiento sociopolítico de Torras i Bages es que no escinde las perspectivas sobrenaturales y naturales o de la eternidad y la temporalidad. Todo forma parte de una misma realidad integrada, sin confusión de planos y cada una con sus propios ámbitos de autonomía. Es decir, cada naturaleza está dotada de sus leyes propias. En el ámbito humano, el derecho natural constituye la regla de la propia naturaleza y se concreta en lo social, a través de la costumbre y de la ley positiva. Obviamente, el orden de la naturaleza ha sido herido por el pecado, lo que explica los desequilibrios y las tensiones sociales existentes. Frente a este postulado, critica el obispo de Vic la posición del naturalismo o materialismo, porque quiere prescindir de la esfera sobrenatural en el análisis de la realidad humana.

${ }_{9}^{9}$ Cf. El pensamiento político de Enrique Ramière, Tesis de Doctorado, Universidad Pontificia Comillas, Madrid, 1991, promanuscripto. 
Estamos, por consiguiente, ante una mirada dirigida a lo sustancial, sin olvidar lo accidental o circunstancial. Ciertamente, no siempre se trata de un discurso hilvanado de razonamientos y silogismos. Normalmente, se trata de un procedimiento dialéctico, que conjuga aparentemente categorías opuestas que desenvuelven integradas el juego de las categorías de la gracia y de la naturaleza.

Desde estos principios generales, Torras i Bages a lo largo de toda su obra concibe y desarrolla una eclesiología muy armónica. Jesucristo es Rey y cabeza de la Humanidad, que en cuanto sujeta a él, forma su Iglesia, la Humanidad sobrenaturalizada. Iglesia dotada de un «cuerpo místico», organizada de conformidad con una constitución jerárquica, presidida por el Vicario de Cristo, el Romano Pontífice, y gobernada por los prelados. Especialmente reseñable es el romanismo de Torras i Bages, que contempla a Pedro y a sus sucesores como piedra fundamental de la Iglesia, signo de unidad del linaje humano y principio espiritual de la Humanidad, el garante de la libertad política, un árbitro entre las potencias internacionales. Esta jurisdicción universal del Papa motivaba que ostentara también un poder temporal, tal y como se le había reconocido históricamente. En el seno de la Iglesia se ha podido gestar la civilización occidental, animada por las virtudes teologales de la fe, la esperanza y la caridad. Precisamente, por su carácter sobrenatural, la Iglesia no prefiere una forma política determinada, siempre y cuando se garantice la prevalencia del principio espiritual en la comunidad política. Antes, al contrario, la gran tarea que tienen los cristianos, para el prelado catalán, es sobrenaturalizar el mundo. Él, defensor de la tradición catalana, proclama la necesidad de desapegarse de las instituciones históricas, caducas y mudables, para adaptarlas a las necesidades modernas. En esta tarea, por cierto, el clero debe jugar una función indirecta pero irremplazable, por cuyo motivo le es exigible una exquisita neutralidad en las cuestiones más opinables.

En Torras i Bages encontramos también interesantes reflexiones sobre la antropología cristiana, desde unas categorías escolásticas en diálogo con las inquietudes del mundo moderno, como es la cuestión de la libertad o de la dignidad de la conciencia humana. De todas maneras, estamos ante un autor profundamente antiliberal, que reclama, acaso desde 
planteamientos menos continuistas con la propia tradición política española y catalana, el respeto por la condición cristiana de la comunidad política, formada básicamente por cristianos. Por ello, se mostraría muy crítico también con la democracia parlamentaria liberal, impulsada a su juicio por la secta masónica, por querer sojuzgar la conciencia social, al igual que lo habían hecho otras formas políticas tiránicas en otros momentos.

A partir de esta base podemos ya reconstruir los presupuestos pre-políticos sobre los que se basa la exposición de la teoría política de Torras i Bages y especialmente su regionalismo. Parte de una filosofía clásica de la política, en lo que Torras i Bages señala que la vida en la región es una concreción de la vida política. Recordemos que para Aristóteles y Santo Tomás de Aquino, la civitas es la comunidad política perfecta, en la que se asegura la justicia legal y particular. Pero lo que une esta ciudad es la amistad de sus miembros. Con arreglo a esta amistad, basada sobre la virtud, en su seno se dan las relaciones plenificantes entre los ciudadanos, para lo cual se necesita no obstante un plano de cierta igualdad, que permitiría la unidad de miras y obrar respecto de lo esencial, es decir, la concordia social.

La de Torras i Bages es una concepción orgánica, que anuda la variedad de los cuerpos sociales bajo el principio de autoridad de un gobierno que garantiza el cumplimiento de la ley, ordenada al bien común. Autoridad procedente del mismo Dios, que, como era característico en las Españas, se basaba en un modelo patriarcal o monárquico y que por la pietas sujetaba los miembros de la Respublica al Príncipe. Por su parte, los cuerpos sociales, incluyendo las regiones históricas, como Cataluña, en cuanto personas morales, están dotadas de autonomía y se rigen por el principio de subsidiariedad.

La sociedad se basa en tres pilares fundamentales: la religión, la familia y la propiedad no capitalista, en un modelo tradicional y de desarrollo sostenible, que a veces ha sido calificado despectivamente como «pairalisme» ${ }^{10}$. Por el contrario, para Torras i Bages, el socialismo niega de plano toda relación de familia y propiedad, no respetando ninguna institución divina

${ }^{10}$ Afección un tanto excesiva a las cosas «pairals» (en catalán: de los padres o antepasados), a los usos y costumbres tradicionales catalanas. 
o humana. En la cuestión social, Torras i Bages ofrece una serie de principios, considerando intencionalmente al proletariado como una clase social que debe centrar la atención prioritaria de la pastoral del clero. Ante las posturas que postulaban como inevitable el conflicto de clases, en Torras i Bages la caridad debe constituir el antídoto o lenitivo de los problemas sociales a la hora de reconstituir unas relaciones laborales justas y equitativas.

En esta panorámica revisión de los elementos que constituyen una sociedad cristiana, en la línea magisterial de León XIII, Torras i Bages define un tipo de democracia cristiana, como sistema social y no político, en el que se priorice el amor preferencial por los pobres ${ }^{11}$. En cualquier caso, se trata de la antítesis de las democracias modernas, porque el obispo Torras cuestiona el mito de la soberanía popular o nacional que no reconoce instancia superior. En particular, la democracia socialista le merece el juicio de sectaria y totalitaria. Más en general, la crítica de Torras i Bages se extiende a las manifestaciones de cesarismo, caracterizado por las extralimitaciones del Estado, que se erige en el único legislador y pretende convertirse en director espiritual de la sociedad. En este bloque, se subrayan las notables intervenciones del Obispo catalán en defensa de la escuela católica, frente a los planes de introducción en una sociedad predominantemente cristiana de las escuelas neutra, cuya neutralidad sería más bien aparente, porque disimuladamente se inspira en la ideología del poder político, en este caso, ya descristianizado y que quiere descristianizar la sociedad.

Particularmente, desde estos postulados, Torras i Bages elabora una filosofía o teología política del pueblo catalán, tratando de hallar por la causa formal su principio de movimiento, su naturaleza y espíritu. No olvidando que Dios es autor de dicha naturaleza, en su ser histórico, y, en general, de la comunidad política. En otras palabras, para el Dr. Torras Cataluña es obra de Dios. Atribuye además a Cataluña la categoría de «persona», cuya

\footnotetext{
${ }^{11}$ Cuestión evangélica, la de la predilección u opción preferencial por los pobres, que siempre ha estado en el corazón de la Iglesia, siguiendo la misión del mismo Cristo -evangelizare pauperibus (Lc 4, 18)- como señal de advenimiento del Reino: Beati pauperes, quia vestrum est regnum Dei (Lc 6, 20), pauperes evangelizantur (Lc 7,22 ); pero que ha tomado un relieve mucho más intenso desde el Concilio Vaticano II (cf. Lumen Gentium 8 , 23; Gaudium et Spes 1, 69).
} 
identidad o personalidad unifica la variedad de una región compuesta por individuos, que también son miembros de familias, municipios, corporaciones y otros cuerpos sociales.

A su vez, aunque en Torras i Bages esto se declare ciertamente con menor intensidad, la región catalana forma parte de una comunidad política más amplia, la hispánica. España es, en sus palabras, un conjunto de pueblos unidos por la Providencia ${ }^{12}$. Si hemos hablado de una filosofía política del pueblo catalán, esta, como veremos, entraña también en Torras i Bages una filosofía hispánica conectada con la primera. Ante el decaimiento de la monarquía española tradicional, el objetivo del regionalismo torrasiano pretende rehacer unos órganos regionales fuertes.

Así las cosas, adquiere capital importancia en el sistema del Dr. Torras el concepto de la patria, causa de nuestro ser social, compuesta de un elemento espiritual y material. La tierra de los padres es la parte del linaje humano más identificada con nosotros, por vínculos de sangre y costumbres. Esta patria, en efecto, se asienta sobre una región geográfica, con unas condiciones físicas, psicológicas, espirituales, religiosas y culturales. Por ello, la patria o región funcionan como un «molde social». Dado que la vivencia de la patria engendra un sentimiento instintivo hacia ella, complementario al familiar, nacional y humano, es muy importante la idea de patria que se tenga. Ante este planteamiento, el Estado, en Torras i Bages, en cuanto comunidad política, es también una entidad natural. Con todo, el liberalismo moderno, para nuestro autor, ha creado un Estado prácticamente artificial, que explicaría la disminución de la vinculación afectiva con el mismo.

En resumidas cuentas, el regionalismo para Torras i Bages es una expresión del patriotismo. Se trata de un amor humilde al propio modo de ser, que es una extensión del amor al prójimo, puesto que nos hace amar el bien de nuestro país. Por consiguiente, este regionalismo constituye una moral social y entraña además una verdadera libertad. Por su condición instintiva, no puede ser impuesto desde arriba.

\footnotetext{
${ }^{12}$ Cf. Obres Completes, Publicacions de l'Abadia de Montserrat, Barcelona 1984, v. I, p. 229.
} 
Defiende el Dr. Torras que por estas razones la Iglesia también es regionalista, puesto que el regionalismo dispone adecuadamente a una sociedad determinada para sobrenaturalizarla. Al mismo tiempo, la región encuentra su plenitud en la Iglesia, plenitud que, como advertiría críticamente el ilustre jurista Juan Berchmans Vallet de Goytisolo, también debería encontrarla en la comunidad política perfecta, si bien Torras i Bages no incide especialmente en ello, sin negarlo (dado que, en su ideal medieval, la vida regional quedaba integrada en la comunidad política mayor, bajo la autoridad del Monarca o Emperador y presidida por la misma fe).

Sin embargo, la especial atención de Torras i Bages por su Cataluña natal no significa menoscabo o desprecio del resto de España. Al revés, su regionalismo pretende convertirse en una solución de los resentimientos creados, de modo que contribuya a la verdadera unión entre los pueblos hispánicos. Ello será tanto más fácil cuando se admita que dicho elemento de cohesión es la fe católica, como elemento intrínseco y esencial de la constitución histórica española. Ello fue lo que sucedió en el Compromiso de Caspe, donde se convirtieron en jurídicos los lazos morales configurados por la naturaleza y la historia, que unían los pueblos de España. En consecuencia, se debe preservar esta fe, la cual debe ser reconocida públicamente, puesto que el modo natural y espontáneo del pueblo español es católico. Por el contrario, para el Prelado catalán, una España descreída o apóstata firmaría así su sentencia de muerte, siguiéndose de ello su disolución.

El espíritu catalán y español, coinciden así en su contenido. Si en Del espíritu de las leyes Montesquieu ya hablaba del espíritu general de la nación, Torras i Bages asume rectificada la teoría del espíritu nacional a través de sus maestros Llorens i Barba y Duran i Bas, en una versión cristianizada del volksgeist. Ese espíritu, en Torras i Bages, alude a la naturaleza o esencia, el principio formal que explica el dinamismo de una realidad, tal y como se manifiesta en la propia vida social. No es un despliegue hegeliano de la Libertad o Idea, el título que legitima la pretensión autodeterminativa de una nación. En Torras i Bages ese espíritu, que es el cristianismo, es trascendente y no inmanente, por lo que no se absolutiza. De ahí que resulte 
un elemento verdaderamente cohesionador y vivificador, que delimita el ámbito de autonomía y de los propios fines, en este caso de Cataluña.

El producto de este espíritu cristiano en Cataluña, tal y como se evidencia en el tiempo, es la tradición. A su vez, esa tradición catalana expresa el espíritu catalán. La tradición, consiguientemente, nos ayuda a contemplar la verdad política, teniendo en cuenta que la humanidad es de suyo tradicional. A su vez, la propia tradición es generadora y educadora de naciones, pero al mismo tiempo se suscita en la sucesión de los tiempos en una región determinada. En este sentido, la tradición nos manifiesta la ley natural reflejada en la conciencia personal y social de un pueblo. Un pueblo es su tradición, por lo que esta determina la identidad y la personalidad de un pueblo. Aquí Torras i Bages ponderará, especialmente en su libro La tradició catalana, algunas manifestaciones sociales y culturales de esta tradición, pero especialmente la construcción política del pactismo.

En este punto podríamos extender a Torras i Bages la crítica que el Prof. Francisco Canals Vidal hacía a las posturas del balmesianismo y del menendezpelayismo por claudicantes. Y es que habría cierta limitación en el pensamiento tradicionalista que no alcanzara a juicios concretos sobre la vida más actual de una sociedad. Este esencialismo lo podemos detectar en Torras i Bages cuando marca distancias o descarta en su catálogo de pensadores tradicionales catalanes a los últimos representantes de dicha escuela en el siglo XIX, a saber, los escritores realistas y carlistas. No creo que sea por mera ignorancia. Lo más probable es que estemos ante un silencio deliberado, en su intención de extender su influencia doctrinal a ámbitos liberales, prevenidos frente al carlismo.

Sea como fuere, Torras i Bages se siente muy cómodo invocando la tradición política de la Corona de Aragón vigente hasta el antes citado Decreto de Nueva Planta, conocida como pactismo. La práctica del pactismo catalán implicaba toda una teoría filosófica, política y jurídica subyacente, entroncada con el orden jurídico del ius commune de la Cristiandad. Era un sistema que permitía, en opinión de Torras i Bages, el gobierno del país por el país, contrapuesto a los principios del cesarismo y del liberalismo. Y aunque desde el historicismo 
progresista catalán del siglo XIX, se quiso leer en el pactismo un antecedente de la democracia moderna, Torras i Bages, acudiendo a Eiximenis, muestra las radicales diferencias de base entre el pactismo histórico y el contractualismo moderno, ejemplificado en Rousseau.

En definitiva, tras el análisis filosófico e histórico de las bases de un sistema político cristiano y tradicional, tomando como referencia Cataluña, Torras i Bages se atreve a formular un programa de regionalismo ortodoxo o «debidamente practicado», al servicio de la defensa de los ideales tradicionales. Regionalismo opuesto al centralismo y al nacionalismo de cariz liberal y revolucionario. Este regionalismo tradicional debe basarse en los consabidos pilares sociales de la religión, propiedad y familia. En ello se constata que Torras i Bages no acentúa la figura de la monarquía como fundamento de un nuevo orden cristiano. Sí que elabora una defensa aguerrida de la lengua catalana, puesto que forma parte innata de la región y representa la comunicación de las propias formas. Por tanto, el uso de la lengua propia es para él de derecho natural y la vindica, en los ámbitos de la predicación y del catecismo, por razones eminentemente pastorales, ancladas en una tradición canónica secular.

Para el regionalismo, hablar de propuestas de autonomía para Cataluña debe presuponer evitar someterse a influencias de modas y leyes extranjeras. Ante todo, se trata de vivir de acuerdo con la propia ley, esto es, vivir de acuerdo a la esencia más íntima, es decir, cristianamente. Precisamente, según Torras i Bages, ello debe precavernos de las invasiones de la burocracia, que niega tal autonomía y que pretende construir un país sobre bases racionalistas y voluntaristas, sin Dios. Esta pretensión de autodeterminación, en suma, para Torras i Bages, supondría empeñarse en construir una «Cataluña de papel».

Por todo ello, el Dr. Torras asume conscientemente el catalanismo ambiental con la intención de corregir las tendencias progresistas y laicistas concurrentes, que él atribuía a Valentín Almirall. En su abstencionismo político, se siente llamado a intervenir indirectamente en dicho catalanismo, desde su condición sacerdotal. Para él, ese catalanismo es loable dado que busca fomentar la participación popular en la vida del país. En efecto, más o menos 
abiertamente, nuestro autor simpatizaba con la obra política llevada a cabo por la Lliga Regionalista ${ }^{13}$.

\section{Conclusiones}

Para terminar la presente exposición, brindo algunas conclusiones de la investigación llevada a cabo sobre el pensamiento político de Torras i Bages.

Así, podemos observar que es un autor tradicional y tradicionalista. Es tradicional porque defiende sin complejos el legado espiritual de Cataluña y de las Españas, conformado por una fe operativa y desde una perspectiva aristotélico-tomista evidente. Pero es tradicionalista en cuanto está condicionado por el ambiente romántico e historicista de su época, del que no consiguió despegarse. Ello le hace preterir, por ejemplo, algunas referencias del pensamiento catalán tradicional más inmediatas y lo aleja de la representación política de aquel pensamiento: el carlismo.

Ciertamente, Torras i Bages no asume plenamente el hecho de que la tradición catalana, para mantenerse, no debería desvincularse o desentenderse de la común tradición española. Torras i Bages se justificaba, acaso, queriendo acercarse pastoralmente a los ambientes más heterogéneos de la «Renaixença», queriendo recrear una cultura cristiana en la Cataluña de la modernidad. Se trasluce este tradicionalismo condicionado en una afirmación menos intensa del ser español, así como cierta desafección actual de la monarquía tradicional, haciendo profesión de cierto indiferentismo político.

El regionalismo o catalanismo de Torras i Bages no es nacionalista. Su ortodoxia y su teología de la historia le impidieron caer en invocaciones de «un derecho a decidir» de un pueblo

\footnotetext{
${ }^{13}$ Se trata de un partido de ideología catalanista conservadora, fundado en 1901 (aglutinando el Centre Nacional Català y la Unió Regionalista), destinado a ejercer la hegemonía política en Cataluña durante los primeros veinte años del siglo XX. Era un partido moderno, con presencia territorial y una línea de actuación centralizada desde la Comisión de Acción Política. Su ideología era nacionalista (la sección juvenil se llamaba Juventut Nacionalista), si bien adoptaba una estrategia regionalista. En 1933 cambió su denominación por el de Lliga Catalana.
} 
catalán pretendidamente soberano, lo cual sería incompatible con una lectura providencialista de la historia. En este sentido, no encontramos en él atisbo del principio de nacionalidades. Al contrario, quiere ser un guía espiritual del catalanismo, para mantenerlo en la órbita del cristianismo. En este sentido, es un catalanista para el cristianismo.

Me inclino a pensar que Torras i Bages, imbuido de la atmósfera romántica dominante en la cultura de la Barcelona de la segunda mitad del siglo XIX, pudo experimentar cierto desenfoque en sus juicios políticos más concretos y actuales. Así, no supo ver que el nacionalismo catalán de alguno de sus amigos o discípulos constituía una sibilina ruptura con la tradición que él predicaba y defendía. Por este motivo, desde el pensamiento tradicional actual, se ha hablado de un fracaso de la propuesta catalanista y regionalista de Torras i Bages, toda vez que su legado se ha visto frustrado respecto a su propósito evangelizador, resultando incluso antitético al modelo de sociedad tradicional y cristiana que propugnaba para Cataluña. Actualmente, la pretendida inculturación local de la fe ha dado lugar con frecuencia a una subordinación de la misma y, por ende, su desvirtuación, por las exigencias culturales del nacionalismo local, cediendo ante el espíritu del mundo.

Por fin, entiendo que sigue siendo apremiante la llamada de Torras i Bages a volver a las raíces de la patria, para actualizarlas. En consonancia con el planteamiento torrasiano, es siendo cristiana que Cataluña es verdaderamente catalana. Y siendo catalana es hispánica. Y es que la comunión de las naciones, regiones o pueblos españoles, que se extiende a la comunidad de naciones hispanoamericanas, se funda en un vínculo sobrenaturalizado por la misma fe en Cristo Salvador. 


\section{Referencias}

Bordas Prószynski, M., "Biografia, home del seu temps” en Crispí, M. (ed.), Torras i Bages, home de l'eternitat, Bisbat de Vic, Vic 2016, pp. 39-63.

Corts i Blay, R., La qüestió catalana en l'Arxiu Secret Vaticà. De la Restauració a Primo de Rivera (1875-1923), Ateneu Universitari Sant Pacià, Barcelona 2017.

Díaz, E., Sociología y Filosofía del Derecho, Ed. Taurus, Madrid 1980.

Grossi, P., L'Europa del diritto, Ed. Laterza, Bari 2016.

Marfany, J.-Ll., Nacionalisme espanyol i catalanitat. Cap a una revisió de la Renaixença, Ed. 62, Barcelona 2017.

Miró i Comas, A., Les arrels tomistes i agustinianes de l'estètica de Josep Torras i Bages, Publicacions de l'Abadia de Montserrat, Barcelona 2018.

Miró i Comas, A., "La Ciutat de la Bellesa. Regionalisme i bellesa en el pensament de Josep Torras i Bages" en Ausa, vol. 28, núm. 181-182, 2018, pp. 879-900.

Miró i Comas, A., "La tradición como conciencia de los pueblos en Jaume Balmes y Josep Torras i Bages" en Revista interamericana de investigación, educación y pedagogía, vol. 12, núm. 1, Enero-Junio, 2019, pp. 117-134.

Palomar Maldonado, E., El pensamiento político de Enrique Ramière, Tesis de Doctorado, Universidad Pontificia Comillas, Madrid, 1991, promanuscripto.

Pueyo Velasco, J., La plenitud terrena del Reino de Dios en la Historia de la Teología, 2 vols., Ed. Cor Iesu, Toledo 2020.

Saranyana, J.-I., "Un historicista que estimava la llibertat. Torras i Bages repensa l'univers catalanesc" en Ausa, vol. 29, núm. 185, 2020, pp. 485-500.

Torra Bitlloch, J., "La doctrina de las dos ciudades en Agustín de Hipona" en Revista interamericana de investigación, educación y pedagogía, vol. 12, núm. 1, Enero-Junio, 2019, pp. 73-85.

Torras i Bages, J., Obres Completes, 10 vols., Publicacions de 1'Abadia de Montserrat, Barcelona 1984-1994.

Torras i Bages, J., Epistolari, 5 vols., Publicacions de l'Abadia de Montserrat, Barcelona 1994-1998 (prólogo, transcripción y anotación de Jaime Medina). 
REVISTA INTERNACIONAL DE FILOSOFÍA TEÓRICA Y PRÁCTICA

Volumen 1. Número 1. Enero - Junio 2021

ISSN: 2745-0333 (En línea) 